\title{
Falls in the elderly: a major public health challenge with some encouraging developments. A mini review
}

Thomas Mattig

Health Promotion Switzerland, Bern, and Institute of Global Health, University of Geneva, Switzerland

Falls are among the major causes of morbidity and mortality in the elderly. Well-known risk factors are reduced physical activity, obstacles in the environment, balance and gait disorders, depression and neurological diseases. The gravity of trauma related to falls has been studied extensively, the main predictors of a harmful development within 12 months of a fall being dementia, old age, the level of dependency and restricted mobility. Efficient prevention interventions do exist, especially exercise-based interventions and assessment and modification of the home environment.

A shift in the trend of falls among the elderly has indeed been reported in several Western countries: since the 1990s, rates of fall-related injuries have declined in countries such as Finland, Sweden, Canada and Switzerland.

Key words: falls, elderly, prevention, trends, risk factors

Received: January 8, 2020

Accepted: January 22, 2020

\section{Correspondence}

\section{Thomas Mattig}

Gesundheitsförderung Schweiz, Wankdorfallee 5,

3014 Bern, Switzerland

Tel.: +4131350 0404

E-mail:Thomas.Mattig@promotionsante.ch

\section{Conflict of interest}

The Author declare no conflict of interest

How to cite this article: Mattig T. Falls in the elderly: a major public health challenge with some encouraging developments. A mini review. Journal of Gerontology and Geriatrics 2020;68:180-3. https://doi. org/10.36150/2499-6564-428

C Copyright by Società Italiana di Gerontologia e Geriatria (SIGG)

\section{(c) (i) $(9)$}

\section{OPEN ACCESS}

This is an open access article distributed in accordance with the CC-BY-NC-ND (Creative Commons Attribution-NonCommercial-NoDerivatives 4.0 International) license. The article can be used by giving appropriate credit and mentioning the license, but only for non-commercial purposes and only in the original version. For further information: https://creativecommons.org/licenses/by-nc-nd/4.0/deed.en

\section{INTRODUCTION}

Falls are among the major causes of morbidity and mortality in the elderly. According to a systematic review, every year about one-third of people aged 65 and over, and nearly half of those over 80 years of age, suffer from a fall. Between one-fifth and one-third of them suffer moderate to severe injuries, including fractures ${ }^{1}$. The prevalence of falls is increasing due to the aging of the population. This makes preventing falls among the elderly and strengthening bone health in general a major public health challenge ${ }^{2}$, albeit not an insurmountable one. Indeed, as many studies report, the main risk factors of falls among the elderly are well documented, even though "fall risk assessment tools currently used for the elderly did not show sufficiently high predictive validity for differentiating high and low fall risks" ${ }^{3}$.

\section{RISK FACTORS}

Several systematic reviews on the topic of risk factors of falls in the elderly have been published. Following are four examples:

- according to a systematic review of observational studies ${ }^{4}$, sedentariness increases the risk of falls, while physical activity reduces it. Physical activity also reduces the risk of fall-related injuries (particularly fractures). According to the results of the meta-analysis performed on 
23 articles, the combined odds ratio for physical activity and falls was 0.75 (95\% Cl: 0.64-0.88); the combined odds ratio for physical activity and fallrelated injuries was 0.59 (95\% Cl: 0.45-0.74); and the combined odds ratio for sedentary lifestyle and falls was 1.14 (95\% Cl: 1.10-1.82);

- another systematic review of observational studies focusing on the influence of the environment confirms that the home environment and the use of walking aids are significantly associated with an increased probability of falling 5 ;

- according to a systematic review of prospective studies on risk factors for falls in older adults living in community settings ${ }^{6}$, the main risk factors for falls are a history of falls $(O R=2.8)$, gait disorders $(O R=2.1)$, the use of walking aids $(O R=2.2)$, dizziness $(\mathrm{OR}=1.8)$, Parkinson's disease $(\mathrm{OR}=2.7)$, and antiepileptic drug therapy $(\mathrm{OR}=1.9)$. All these risks are further increased among recurrent fallers;

- another recent review and meta-analysis identified 25 prospective studies on the risk of falling related to depressive symptoms ${ }^{7}$. A high level of depressive symptoms at baseline was associated with an increased likelihood of falling by $52 \%$ (14 studies: pooled $\mathrm{OR}=1.46$, 95\% Cl: 1.27-1.67; 6 studies: pooled $\mathrm{RR}=1.52,95 \%$ Cl: 1.19-1.84). There was no observed difference in the risk of falling between elderly people living in institutions and those living in the community.

\section{GRAVITY OF FALLS IN THE ELDERLY}

The gravity of trauma related to falls is well assessed. A prospective study from Basel, Switzerland, may serve as an example. It examined the outcome at 12 months of 272 people aged 65 and over that were treated for a fracture of the femoral neck after falling 8 :

- the mean age was 84 years (standard deviation: 7.5). Before the fracture, $70 \%$ of the patients lived in a community environment, 59\% could walk without help or with a walking cane, and " $26 \%$ needed a walker, a wheelchair or were bedridden before the fracture";

- a diagnosis (or suspected diagnosis) of dementia at entry was reported in $35 \%$ of the patients. Overall mortality at 12 months was $22 \%$ (12\% in patients living in a community setting before the incident, and $44 \%$ in patients in institutional settings). Death rates were significantly higher among the older ones;

- among the patients living in a community setting before the incident, $17 \%$ had moved to an institutional setting 12 months after the fracture. One-third (30\%) reported problems with increased dependency for activities of daily life;
- the main predictors of a harmful development at 12 months were dementia, old age, level of dependency in activities of daily life, and restricted mobility.

\section{PREVENTION STRATEGIES}

In 2012, a Cochrane review on fall prevention interventions targeting the elderly in a community environment ${ }^{9}$ analyzed 159 randomized controlled trials representing 79,193 participants. The authors concluded that the following interventions are effective in preventing falls:

- multi-component group exercises reduce the rate of falls (rate ratio $=0.71,95 \% \mathrm{Cl}: 0.63-0.82$ ) and the risk of falling by $15 \%$ (risk ratio $=0.85,95 \% \mathrm{Cl}$ : 0.76-0.96);

- multi-component home exercises reduce the rate of falls (rate ratio $=0.68,95 \% \mathrm{Cl}: 0.58-0.80$ ) and the risk of falling by $22 \%$ (risk ratio $=0.78,95 \% \mathrm{Cl}$ : 0.64-0.94);

- with Tai Chi, the reduction in the rate of falls is at the limit of statistical significance (rate ratio $=0.72,95 \%$ Cl: 0.52-1), but the reduction of the risk of falling, around $29 \%$, is significant (risk ratio $=0.71,95 \% \mathrm{Cl}$ : 0.57-0.87);

- overall, exercise-based interventions reduce the risk of fractures related to falling by $66 \%$ (risk ratio = 0.34, 95\% Cl: 0.18-0.63);

- assessment and modification of the home environment reduce the relative risk of falling by approximately $12 \%$ (rate ratio $=0.81,95 \% \mathrm{Cl}$ : 0.68-0.97; risk ratio $=0.88,95 \% \mathrm{Cl}: 0.80-0.96)$. These interventions are even more effective when they are targeted at high-risk individuals;

- multifactorial interventions that incorporate an individualized risk assessment reduce the rate of falls (rate risk $=0.76,95 \% \mathrm{Cl}: 0.67-0.86$ ) but not the risk of falling.

A more recent systematic review on the benefits of resistance training in physically frail elderly persons ${ }^{10}$ mentioned a significant reduction in falls after 12 weeks in three out of four studies. And a 2018 updated evidence report and systematic review for the U.S. Preventive Services Task Force concluded: "Multifactorial and exercise interventions were associated with fall-related benefit, but evidence was most consistent across multiple fall-related outcomes for exercise. Vitamin D supplementation interventions had mixed results, with a high dose being associated with higher rates of fall-related outcomes" ${ }^{11}$.

\section{RECENT DEVELOPMENTS}

Remarkably, we are observing a downward shift in the trend of falls among the elderly in several Western 
countries ${ }^{12}$, although it is unclear what role such factors as the mean BMI increase, the changes in lifestyle and environment, or ramped-up prevention campaigns may have played. For example, a population-based study of Finns 80 years of age and older has found that the ageadjusted incidence of fall-related injuries has stalled since the late 1990s and is even declining for men and women of all ages, with the exception of men over the age of $90{ }^{13}$. A similar development has been observed in Sweden, with a stabilization of the absolute number of hip fractures between 1987 and 2009, a decreased incidence rate "for all age- and sex-specific groups, with the largest changes in the younger age groups and among women" ${ }^{14}$. In Canada, age-standardized incidence rates of hip fractures have been declining since about 1985, and this trend has been accelerating in recent years ${ }^{15}$. In Austria, by contrast, no stabilization of age-adjusted incidence rates could be observed between 1994 and 2006, except among women aged 80 to $84{ }^{16,17}$. In Geneva, Switzerland, between 1991 and 2000, the total number of hip fractures has stabilized and the age of women with a fracture has increased significantly ${ }^{18}$. The age-adjusted incidence showed a significant decrease of $-1.4 \%$ among women $(95 \% \mathrm{Cl}$ : -2.6--0.1) but not among men. This decrease is mainly attributable to a $1.9 \%$ annual decline in the incidence of hip fractures among women living in institutional settings ${ }^{19}$. For the whole of Switzerland, there has been a reduction in the number of hospitalizations for hip fractures over the past decades (-15\% for women and $-11 \%$ for men aged 45 and over), but this is more than offset by an increase in the number of osteoporotic nonhip fractures $(+24.8 \%$ for women and $+13.8 \%$ for men aged 45 and over). As a result, the burden on the healthcare system continues to increase ${ }^{20,21}$.

\section{CONCLUSIONS}

Yet implementation of validated community-based fall prevention programs has to contend with a number of obstacles: lack of time among professionals, low motivation among the elderly, insufficient cooperation between service providers, lack of participation in specific exercises to develop balance and limited adherence to programs, especially among people of low socio-educational background, obese people, people in poor subjective health, people with difficulties walking or using a walking aid, and people with a history of prior falls 22,23 .

As a result, the attractiveness of and adherence to programs should be recognized as key priorities, all the more since the costs related to falls among the elderly represent a significant share of global health costs ${ }^{24-26}$.

\section{References}

1 Ambrose AF, Paul G, Hausdorff JM. Risk factors for falls among older adults: a review of the literature. Maturitas 2013;75:51-61.

2 Bergström U, Jonsson H, Gustafson Y, et al. The hip fracture incidence curve is shifting to the right. Acta Orthopaedica 2009;80:520-4.

3 Park S. Tools for assessing fall risk in the elderly: a systematic review and meta-analysis. Aging Clin Exp Res 2018;30:1-16.

4 Thibaud M, Bloch F, Tournoux-Facon C, et al. Impact of physical activity and sedentary behaviour on fall risks in older people: a systematic review and meta-analysis of observational studies. Eur Rev Aging Phys Activ 2011;9:5-15.

5 Letts L, Moreland J, Richardson J, et al. The physical environment as a fall risk factor in older adults: systematic review and meta-analysis of cross-sectional and cohort studies. Aus Occup Ther J 2010;57:51-64.

6 Muir SW, Berg K, Chesworth B, et al. Quantifying the magnitude of risk for balance impairment on falls in communitydwelling older adults: a systematic review and meta-analysis. J Clin Epidemiol 2010;63:389-406.

7 Kvelde T, McVeigh C, Toson B, et al. Depressive symptomatology as a risk factor for falls in older people: systematic review and meta-analysis. J Am Geriatr Soc 2013;61:694-706.

8 Pretto M, Spirig R, Kaelin R, et al. Outcomes of elderly hip fracture patients in the Swiss Healthcare System. Swiss Medical Weekly 2010;140:w13086.

9 Gillespie LD, Robertson MC, Gillespie WJ, et al. Interventions for preventing falls in older people living in the community. Cochrane Database System Rev 2012:CD007146.

10 http://onlinelibrary.wiley.com/doi/10.1002/14651858. CD007146.pub3/abstract John Wiley \& Sons, Ltd.

11 Lopez P, Pinto RS, Radaelli R, et al. Benefits of resistance training in physically frail elderly: a systematic review. Aging Clin Exp Res 2018;30:889-99.

12 Guirguis-Blake JM, Michael YL, Perdue LA, et al. Interventions to prevent falls in older adults: updated evidence report and systematic review for the US Preventive Services Task Force. JAMA 2018;319:1705-16.

13 Cooper C, Cole ZA, Holroyd CR, et al. Secular trends in the incidence of hip and other osteoporotic fractures. Osteoporosis Int 2011;22:1277-88.

14 Korhonen N, Niemi S, Palvanen M, et al. Declining ageadjusted incidence of fall-induced injuries among elderly finns. Age Ageing 2012;41:75-9.

15 Nilson F, Moniruzzaman S, Gustavsson J, et al. Trends in hip fracture incidence rates among the elderly in Sweden 1987-2009. J Public Health 2013;35:125-31.

16 Leslie WD, O'Donnell S, Jean S, et al. Trends in hip fracture rates in Canada. JAMA 2009;302:883-9.

17 Mann E, Icks A, Haastert B, et al. Hip fracture incidence in the elderly in austria: an epidemiological study covering the years 1994 to 2006. BMC Geriatrics 2008;8:35.

18 Mann E, Icks A, Meyer G. Discrepancies in national incidence trends for hip fracture: why does Austria have 
such a high incidence? Wiener Klinische Wochenschrift 2010;122:126-8.

19 Chevalley T, Guilley E, Herrmann FR, et al. Incidence of hip fracture over a 10-year period (1991-2000): reversal of a secular trend. Bone 2007;40:1284-9.

20 Chevalley T, Herrmann FR, Rizzoli R, et al. Tendances séculaires des fractures de hanche. Ostéoporose 2011;299:1294-8.

21 Lippuner K, Popp AW, Schwab P, et al. Fracture hospitalizations between years 2000 and 2007 in Switzerland: a trend analysis. Osteoporosis Int 2010;22:2487-97.

22 Lippuner K, Grifone S, Schwenkglenks M, et al. Comparative trends in hospitalizations for osteoporotic fractures and other frequent diseases between 2000 and 2008. Osteoporosis Int 2011;23:829-39.
23 Hester AL, Wei F. Falls in the community: state of the science. Clin Interv Aging 2013;8:675-9.

24 Merom D, PyeV, Macniven R, et al. Prevalence and correlates of participation in fall prevention exercise/ physical activity by older adults. Preventive Med 2012;55:613-7.

25 Gannon B, O'Shea E, Hudson E. Economic consequences of falls and fractures among older people. Irish Med $J$ 2008;101:170-3.

26 Heinrich S, Rapp K, Rissmann U, et al. Cost of falls in old age: a systematic review. Osteoporosis Int 2009;21:891-902.

27 Florence CS, Bergen G, Atherly A, et al. Medical costs of fatal and nonfatal falls in older adults. J Am Geriatr Soc 2018;66:693-8. 